\title{
DEVELOPMENT OF A METHOD FOR TESTING DEHYDRATION TOLER- ANCE IN RICE (ORYZA SATIVA L) AND ITS APPLICATION TO A RECOM- BINANT INBRED LINE POPULATION
}

\author{
${ }^{1}$ Ranawake $\mathrm{AL}^{*},{ }^{2}$ Nakamura C \\ ${ }^{1}$ Faculty of Agriculture, University of Ruhuna, Mapalana, Kamburupitiya, Sri Lanka \\ ${ }^{2}$ Graduate School of Science and Technology, Kobe University, Japan1-1 Rokkodai, Nada-ku, Kobe, Japan
}

Accepted: 8 June, 2011

\begin{abstract}
A recombinant inbred line population derived from Japonica rice cultivar Hyogokithanishiki and Indica rice cultivar Hokuriku-142 is a valuable source for genetic and molecular studies as these two parents have different origins. Characterization of the two parents under different biotic and abiotic stress conditions exploits novel research areas such as QTL analysis. In the present study two parents were evaluated for dehydration tolerance using Petri dish method and nursery box method. Average root length, shoot length, root dry matter and shoot dry matter weight were evaluated in each method. Shoot length in nursery box method gave a significant difference between two cultivars with Hygokithanishiki dehydration tolerant and Hokuriku-142 dehydration susceptible. The method was applied to evaluate 163 recombinant inbred lines (RILs) derived from the two parents for dehydration tolerance. The trait showed a normal distribution in the population with some transgressive lines expressing greater dehydration tolerance than dehydration tolerant parent Hyogokithanishiki. Therefore nursery box method is proposed as a reliable method for the evaluation of dehydration tolerance of rice cultivars and this method is suitable for evaluating germplasm collections and breeding populations for dehydration tolerance in rice breeding.
\end{abstract}

Key words: Rice, Bioassay, Breeding, Dehydration Tolerance, Drought Resistance

\section{INTRODUCTION}

Drought is the single greatest factor limiting rice production in approximately 46 million ha of Asia where rice is the main food (Pandey 2000). The conventional breeding techniques have recently been integrated with more efficient phenotyping involving molecular markers and genomic technologies to improve drought tolerance by exploitation of the broad genetic diversity in the primary gene pool of rice (Lafitte et al. 2004). There are two options for the management of crops in water limiting environments: the agronomic and the genetic management. Development of this genetic management technology requires robust, reproducible, simple, and rapid field, pot, and laboratory screening methods for identification of traits of drought tolerance in germplasm, and incorporation of the same in high-yielding varieties using conventional and biotechnological tools.

Drought tolerance is considered to be a difficult topic as it is not possible to define or measure tolerance with the same clarity or precision as it is for disease resistance or for mor-

\footnotetext{
*Corresponding author : lankaranawake@hotmail.com
}

phological or other physiological traits, nor is it easy to manage experimental drought environments with a high level of control and repeatability. Therefore developing a functional definition of drought tolerance to use in screening programs, designing screening procedures to focus effectively on the target environment, and managing the screening experiments to increase precision in detecting heritable differences in tolerance are repeatedly studied.

The reason of the slow progress in developing drought tolerant rice has been identified as the lack of a specific method for screening the large numbers of genotypes required in breeding for drought (Zeigler and Puckridge, 1995). Phenotyping protocols differ among drought tolerant screening and scoring studies. Many traits, such as root traits (Sun et al. 1995; Champoux, et al. 1995) leaf characters (Champoux et al. 1995; Mitchell et al. 1998), proline accumulation (Yang et al. 1995), membrane stability and osmotic adjustment ( $\mathrm{Li}$ et al. 2005), shoot height (Wang et al. 2005), biomass and panicle characters (Lanceras et al. 2004; Yue et al., 2005) have been considered as drought scoring traits in rice. Other than the- 
se, grain yield (Wang et al. 2005), yield components (Lanceras et al. 2004; Yue et al. 2005; Yue et al. 2008) and harvest index (Babu et al., 2003), have also been scored to evaluate drought tolerance in rice. In an upland rice breeding program in Brazil, secondary traits of low leaf rolling, good panicle exertion, and low level of spikelet sterility have been considered as selection criteria (Pinheiro and Da 2006) for drought tolerance. In root phenotyping, thickness of roots measured at basal or deeper soil layers (Kamoshita et al. 2002a), deepness of roots measured as maximum rooting length (Hemamalini et al. 2000), seminal or adventitious root length (Zheng et al. 2003), or total or deep root dry weight (Yadav et al. 1997) had been reported. However, accurate field phenotyping of mapping populations for drought tolerance has remained complex and difficult. The effectiveness of a drought screening procedure is best measured by the genetic heritabilities achieved for target traits, whether the focus is conventional or marker-assisted plant breeding.

Accurate phenotyping in the initial molecular mapping is the most important pre-requisite to success in selecting for drought resistance. Phenotyping is often said to be inadequate owing to poor measurement techniques, irrelevant manipulation of experimental drought conditions, lack of reliable plant and soil data, and lack of field experts to interpret the results of experiments on plant function under drought stress (Blum et al. 2005). Plant height and flowering time usually are highly heritable and are extensively used in traditional plant breeding (Cooper et al. 1999a). Leaf rolling and canopy temperature (Lafitte et al. 2004; Hirayama et al. 2006), root characters (Zhang et al. 1999, Zhang et al. 2001) are also studied for quick screening of hundreds of lines. Measurement of induced traits such as osmotic adjustment or cell membrane stability could involve greater errors than measurement of constitutive traits because of differences in the degree of water stress if experimental conditions are not precisely controlled.

Most putative drought-resistance traits considered for rice have low heritability and are not consistently correlated with grain yield under drought conditions in the target environments because of the large genetic and environment interactions in rainfed rice as well as the large error variance under dry conditions (Atlin and Lafitte, 2002).

Many different drought tolerant screening or scoring techniques have been reported such as, keeping seedlings in two and half leaf stage in $30 \mathrm{~mL}$ PEG (PEG-6000) solutions in tubes (Zhou et al. 2006), growing seedlings in glasshouse to the 3-leaf stage and then placing in a growth chamber with programmed diurnal changes in light, temperature, and relative humidity followed by a 10-day exposure to growth chamber conditions without irrigation under five widely different environments (O'Toole et al., 1978), comparison in irrigated lowlands and severely water stressed under managed stress conditions in uplands (Atlin et al. 2006), and growing during the dry season (Babu et al. 2003; Lanceras et al. 2004; Lafitte et al. 2004; Wang et al. 2005; Yue et al. 2005). Several studies have been conducted under both well-watered and drought-stressed conditions (Zou et al. 2005; Kumar et al. 2007), and some studies applied multiple stress regimes (Lanceras et al. 2004; Jearakongman, 2005). Rainout shelters can reduce damage from untimely rainfall and in China shelters were used with drip irrigation and drainage systems (O'Toole, 2004; Li et al. 2005; Yue et al. 2005; Liu et al. 2008). However, the high cost of such facilities may limit their widespread use. Raised beds, $30 \mathrm{~cm}$ above ground level to screen drought-resistant genotypes (Hirayama and Suga, 1996) were also practiced in Japan.

Because of independent domestication events for Indica and Japonica subspecies, a broad range of variation of characters within indica and japonica varieties can be expected (Gao et al. 2005). Drought tolerant inbred lines have been identified in different germplasm accessions (Yu et al. 2003; Ali et al. 2004; Lafitte et al. 2004) as new breeding materials for development of drought resistance in rice. In the present study a convenient and reliable method for the evaluation of individuals for drought tolerance was developed and the methodology was applied to evaluate an inbred line population of 163 lines derived from a Japonica and Indica cross to assess the feasibility of the method.

\section{MATERIALS AND METHODS}

A cold tolerant japonica rice cultivar Hy- 
ogokithanishiki used in sake brewing, a cold susceptible Indica rice cultivar Hokuriku-142 and a recombinant inbred line (RIL) population $\left(\mathrm{F}_{6}\right.$ generation) of 163 lines derived from them were used in the study. Hokuriku-142 (Hokuriku) was bred from a cross between a Korean cultivar, 'Milyang 21' and an IRRI line 'IR-2061-214-31' at the Hokuriku Agricultural Experimental Station in Japan. High amylose content and low fatty acid content of Hokuriku142 are favorable characters for better sake brewing in Japan and low fatty acid content causes high sensitivity to low temperatures. The initial cross was done for the development of sake brewing rice and present study was carried out using the same materials after advancing the populations up to $\mathrm{F}_{6}$ generation. Inbred line populations were advanced according to the single seed descent method and were selfed at each generation. The parental rice cultivars were used as controls

For the Petri dish method, seeds of the parental cultivars were surface sterilized by dipping in $70 \%$ ethyl alcohol for 2 minutes and subsequently keeping seeds in 1\% sodium hypoclorite solution for one hour. Seeds were germinated in water at $35^{\circ} \mathrm{C}$ for one week in the dark. Germinated seeds were planted in soil filled Petri dishes and allowed to grow for another one-week. During this period Petri dishes were dipped in a basin of 1ppm Hyponex solution (Toyoba, Japan) and the level of Hyponex solution in the basin was maintained by adding water daily. After one week, Petri dishes with plants were removed out of water (Fig. 1A) and left for drying. After 2 days plants were entirely dried and on the third day (one day after drying) four replicates of each parental line were returned to Hyponex solution for recovery. Another set of 4 replicates was returned to Hyponex solution on the next day (two days after drying) and the other set of four replicates were returned to Hyponex solution on the third day after drying. Plants were allowed to recover in Hyponex solution for a 10-day period (Fig.1B). Length of green shoot, shoot dry matter weight and root dry matter weight of plants were scored at the end of the experiment.

In nursery box method, seeds of parental cultivars were surface sterilized and germinated as described above were planted in nursery boxes $(15 \mathrm{~cm} \times 15 \mathrm{~cm} \times 7.5 \mathrm{~cm})$ so that one replicate of two parental cultivars were in one nursery box side by side. Nursery boxes were kept in a basin of water with 1ppm Hyponex solution and plants were allowed to grow there for two weeks (Fig. 2A). After two weeks, nursery boxes were taken out of the basin and plants were allowed to dry (Fig. 2B). Plants were returned to the basin of water for recovery on the $1^{\text {st }}, 2^{\text {nd }}, 3^{\text {rd }}, 4^{\text {th }}$ and $5^{\text {th }}$ day after the drying period. After 10 days of recovery (Fig. 2C, Fig. $2 \mathrm{D})$, length of green shoot, length of root system (the longest root) and dry matter weight of plants were evaluated.

Considering the results of parental screening, 5 -day drying period in nursery boxes was applied for the evaluation of the inbred line population. Fig. 3 shows the bioassay conditions for evaluation of inbred line population derived from Hyogokithanishiki and Hokuriku-142 for dehydration tolerance.

Experiment was carried out according to complete randomized design and repeated three times. Average green shoot length was used as the parameter to evaluate the inbred line population on the $10^{\text {th }}$ day of the recovery period after 5-day dehydration stress. Experiment was carried out in a growth chamber under control environment condition $\left(25^{\circ} \mathrm{C}, 16 \mathrm{~h}\right.$ photoperiod). Data was analyzed using ANOVA.

\section{RESULTS}

\section{Petri dish method}

All plants of Hyogokithanishiki that were subjected to one day drying period recovered and turned green during the recovery period while only few plants of Hokuriku-142 recovered and turned green during recovery period. All the Hokuriku-142 plants that were subjected to dehydration stress for two days dried completely and did not recover after returning to water Fig. $1)$.

Average green shoot length of the two parental rice cultivars showed almost the same value under the control conditions in Petri dish method. On the first day of dehydration stress, two parental cultivars showed much difference in phenotypic characters and by the second day of the stress the difference was quite prominent. Root length of the seedlings was not measured in this experiment as soil depth and experiment 


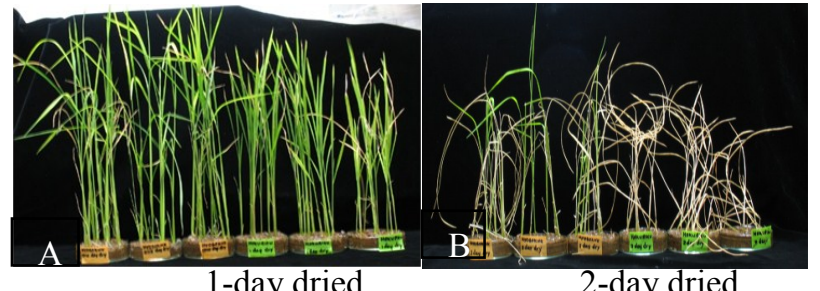

Hyogokithanishiki Hokuriku Hyogokithanishiki Hokuriku

Figure 1 Effect of dehydration stress on two parental rice cultivars grown in Petri dishes. Hyogokithanishiki: Japonica rice cultivar, Hokuriku: Indica rice cultivar Hokuriku-142. A - One day after completely dried and recovered $B$ - Two days after completely dried and recovered

duration was not sufficient for a proper assessment.

Under control conditions and under each dehydration stress condition, Hyogokithanishiki gained higher dry matter weight compared to that of Hokuriku-142. However, none of the parameter was significantly different between two stress regimes in the Petri dish method (Table 1).

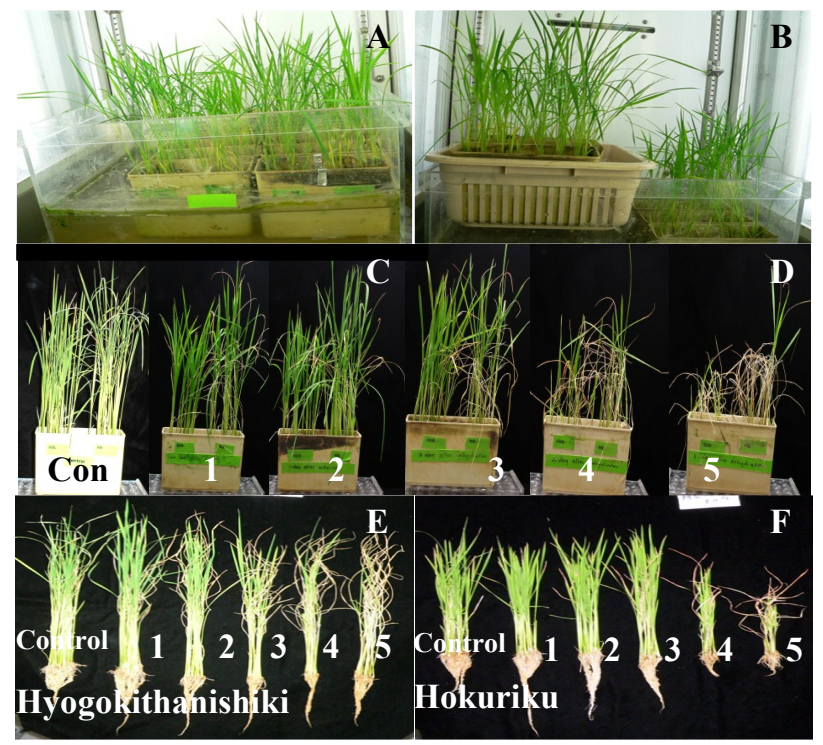

Figure 2 Comparison of two parental rice cultivars subjected to different days of dehydration stress. A. Plants under control condition B. Plants under dehydration condition $C$. Recovered plants after dehydration stress: Control (on left), 1-One-day dehydration, 2-Two-day dehydration, 3-Three-day dehydration, 4Four-day dehydration, 5-Five-day dehydration. In each nursery box plants on the left are Hokuriku-142 while plants on the right are Hyogokithanishiki D. Uprooted Hyogokithanishiki plants after 1 to 5 days of dehydration stress compared with the control $E$. Uprooted Hokuriku-142 plants after 1 to 5 days of dehydration stress compared with control plants
Table 1 The level of significance in each parameter.

\begin{tabular}{llc}
\hline Method & Parameter & P value \\
\hline Petri dish method & Green shoot length & 0.406942 \\
& Shoot dry matter & 0.43433 \\
& Root dry matter & 0.390652 \\
& Shoot length & 0.058062 \\
Nursery box method & Root length & 0.214967 \\
& Shoot dry matter & 0.155056 \\
& Root dry matter & 0.366174 \\
\hline
\end{tabular}

\section{Seed surface sterilization $\downarrow$ \\ Germination for 1 week at $35^{\circ} \mathrm{C}$ in dark}

Two weeks in nursery boxes under normal growth conditions

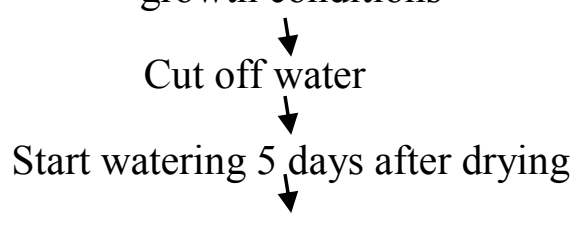

Evaluation of plants after 10 days at normal growth conditions

Figure 3 Bioassay conditions for evaluation of inbred line population for dehydration tolerance.

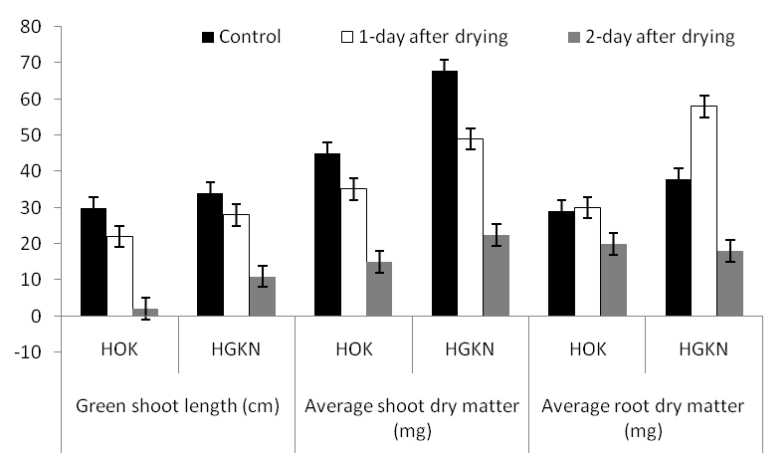

Figure 4 Green shoots length, shoot dry matter weight and root dry matter weight of two parental rice cultivars after dehydration stress in Petri dish method. HGKN: Hyogokithanishiki, HOK: Hokuriku -142 . Data was taken at the $10^{\text {th }}$ day of the recovery period after 1 and 2 days of drying of the seedlings. Standard errors are indicated in bars.

Among parameters evaluated in nursery box method, green shoot length of parental rice cultivars was significantly different at 0.05 probability level (Table 1).

\section{Evaluation of inbred line population for de- hydration tolerance}

The inbred line population was evaluated for drought tolerance by assessing green plant height after a 10 day recovery period following 5 days of drying. The trait showed nearly normal distribution with a skew towards susceptibility (Fig. 5). 


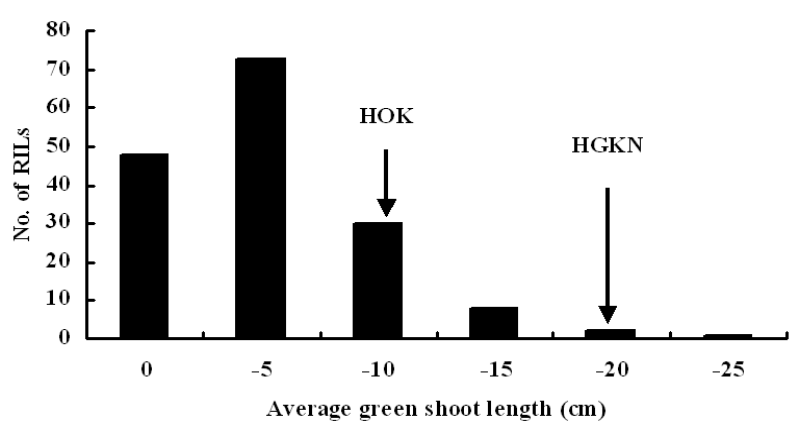

Figure 5 Frequency distribution of the inbred line population for green shoot length after a 5-day dehydration period. Data were recorded on the $10^{\text {th }}$ day of recovery period after a 5-day dehydration stress. Twenty seedlings of each parent and inbred line were subjected to dehydration stress and the experiment was repeated three times.

\section{DISCUSSION}

For efficient screening of dehydration tolerance, Blum (2002) suggested consideration of some aspects of assessing the utility of traits. One was that important drought resistance traits are normally constitutive and not stress adaptive. Constitutive traits, such as flowering time, stay-green trait (delayed onset of leaf senescence), and root depth, were recommended to assess in routine screenings (Blum 2002). Deep and thick root traits contribute to better growth and higher yield under drought stress (Lafitte and Courtois 2002; Babu et al. 2003). However in the present study root length was not studied in Petri dish method, and in nursery box method, root length was not significantly differed between cold tolerant and cold susceptible drought stressed plants. This short period of stress and limited soil depth would not create such difference in two cultivars. Hokuriku142 recorded longer roots compared to Hyogokithanishiki under control conditions (Fig.2D and 2E). Until 3-day dehydration period, Hokuriku-142 recorded longer roots, but from the third day of dehydration, Hyogokithanishiki recorded longer roots. At the fifth day of dehydration, Hygokithanishiki recorded significantly longer roots. The reason would be that, at initial drought stress period, root system of Hokuriku-142 would respond in its maximum capacity while under continued stress conditions Hokuriku-142 failed to survive, but Hygokithanishiki performed better because of its greater tolerance to severe drought stress conditions. Thus, Hokuriku-142 performed better at initial drought stress period than Hyogokithanishiki and Hyogokithanishiki performed better at later stages of drought stress than Hokuriku-142. Overall, analysis of variance of root length did not reveal a significant difference between the two cultivars. This indicates that neither parent carries all of the positive or negative alleles for drought resistance. This is supported by grain yield under drought stress where positive alleles contributed by both parents, as evidenced by transgressive segregation under drought stress (Babu et al. 2003; Lanceras et al. 2004; Xu et al. 2005).

The role of drought adaptive traits towards drought resistance is considered to be greater than stress responsive traits such as active cellular accumulation of compatible solutes (osmoprotectants), antioxidant agents, heat shock proteins, and molecular chaperones, as well as osmotic adjustment and membrane stability (Kamoshita et al. 2008). Plant-type traits (e.g., plant height) and phenology (e.g., flowering time) usually are highly heritable and are extensively used in traditional plant breeding (Cooper et al. 1999a, b). In the present study green shoot length was considered as one of the parameters for evaluation of dehydration tolerance. Hyogokithanishiki recorded higher green shoot length under drought stress (Fig.2D and 2E) compared to Hokuriku. Hence, green shoot length under dehydration can be considered as a useful trait for screening a population derived from the parents used in this study. Constitutive root traits, interacted with drought intensity, have a large effect on extractable soil water during drought (Lilley and Fukai, 1994). This influences expression of both induced and secondary traits such as maintenance of plant water status, canopy temperature, leaf rolling score, and leaf death score (Lilley and Fukai 1994). High dry matter weight of root system of Hyogokithanishiki under severe drought stress is additional evidence for higher dehydration tolerance of Hyogokithanishiki than Hokuriku-142. Umayal et al. (2001) observed that drought tolerant Indica landraces in southern India had thicker roots with wider xylem vessels. Deeper and thicker roots also may occur under upland conditions and some lowland conditions, helping the plant to absorb larger amounts of soil water, thus maintaining higher plant water status (Yoshida and Hasegawa, 1982; Kumar et al. 2004) Average root dry matter weight of Hy- 
ogokithanishiki increased drastically by the first day of dehydration stress compared to control plants but by the second day of dehydration stress both cultivars showed sudden decrease in root dry matter (Fig.4). However, high dry matter accumulation in the root system on the first day of dehydration stress in Hyogokithanishiki indicates its better dehydration tolerance response. However, the nonsignificant difference in root dry matter production of drought tolerant rice cultivars under drought stress has also been reported (Ekanayake et al. 1985; Samson et al. 2002; Kamoshita et al. 2002a; Pantuwan et al., 2004; Yue et al. 2006; Kumar et al. 2007). The measurements of root traits under drought conditions in the field usually have large errors (Pantuwan et al. 2004; Samson et al. 2002), and the broad-sense heritabilities of root traits measured in the field (e.g., Kumar et al. 2007) are in general lower than those measured under hydroponic systems (Ekanayake et al. 1985) and pot systems (Kamoshita et al. 2002a; Yue et al., 2006). Pantuwan et al. (2004) reported that root responses to dry conditions among genotypes in the dry season differed from responses under wet season drought. So, the root trait results of any kind of drought screening under control environmental conditions may deviate more or less from the reality.

Among measured parameters in the present study, only green shoot length of nursery box method was significantly different in two parents at 0.05 probability level (Table 1). Green shoot length of survived rice seedlings on the $10^{\text {th }}$ day of recovery period after 5 days of drying stress on two-week-old seedlings was applied to evaluate dehydration tolerance in inbred line population derived from the two parents used in this study; Japonica rice cultivar Hyogokithanishiki and Indica rice cultivar Hokuriku-142.

The phenotypic distribution in the inbred lines for green shoot length did not show discrete classes but approximately fitted a normal distribution, indicating that green shoot length is quantitatively inherited in nature. Transgressive segregation in both directions was observed for the trait (Fig.5) under 5 day dehydration stress, indicating that both parents transmitted favorable alleles for the trait. The population used in the present study possessed
3 inbred lines with longer green shoot length than drought tolerant Hyogokithanishiki (Fig.5). Phenotypic frequency distributions support the quantitative inheritance of drought tolerance genes. This method can be successfully applied for large scale screening for drought tolerant at seedling stage in rice.

\section{ACKNOWLEDGEMENTS}

Ranawake A.L. wishes to acknowledge Monbukagakusho (Ministry of Education, Culture, Sports, Science and Technology, Government of Japan) for the financial support for postgraduate studies in Japan and Prof. Shinya Yoshida, Hyogo Institute of Agriculture, Forestry and Fishery, Japan for providing plant materials, Prof. Naoki Mori and Prof. T. Ishii for technical support and Prof. Ranjith Pathirana for critical reviewing of the manuscript.

\section{REFERENCES}

Ali AJ, Xu JL, Ismail AM, Fu B, Vijaykumar CHM, Gao YM, Domingo J, Maghirang R, Yu SB, Gregorio G, Yanagihara S, Cohen M, Mackill D and Li ZK 2006 Hidden diversity for abiotic and biotic stress tolerances in the primary gene pool of rice revealed by a large backcross breeding program. Field Crop Res. 97: 66-76.

Atlin, GN, and Lafitte HR 2002 Marker-assisted breeding versus direct selection for drought tolerance in rice. In: N. P. Saxena, and J. C.O'Toole (ed.) Field screening for drought tolerance in crop plants with emphasis on rice. p. 208. Proceedings of an international workshop on field screening for drought tolerance in rice, 11-14 Dec 2002, ICRISAT, Patancheru, India. 502324, and The Rockefeller foundation, New York, 100182702, USA.

Atlin GN, Lafitte HR, Tao D, Laza M, Amante M and Courtois B 2006 Developing rice cultivars for high-fertility upland systems in the Asian tropics. Field Crops Research. 97: 43-52.

Babu RC, Nguyen BD, Chamarerk V, Shanmugasundaram $\mathrm{P}$, Chezhian $\mathrm{P}$, Jeyaprakash $\mathrm{P}$, Ganesh SK, Palchamy A, Sadasivam S, Sarkarung S, Wade LJ and Nguyen HT 2003 Genetic analysis of drought resistance in rice by molecular markers: association between econdary traits and field performance. Crop Science. 43:1457-1469.

Blum A 2002 Drought tolerance - is it a complex trait? In: Saxena NP, O'Toole JC (ed.) Field Screening for Drought Tolerance in Crop Plants with Special Emphasis on Rice: Proceedings of an International Workshop on Field Screening for 
Drought Tolerance in Rice. 11-14 December, 2000, International Crop Research Institute for Semi-arid Tropics, Patancheru, India. Patancheru, India; International Crop Research Institute for Semi-arid Tropics, Rockefeller Foundation, New York, USA. pp. 17-24.

Blum A, Tuberosa R, Nguyen HT and ArausOrtega JL 2005 Conference conclusions and recommendations In: INTERDROUGHT-II. Proceedings of the 2nd International Conference on Integrated Approach to Sustain and Improve Plant Production Under Drought Stress., Rome, Italy, September 24-28. www.plantstress. com/ id2/ID2-Report.pdf.

Champoux MC, Wang G, Sarkaruag S, Mackill DJ, O'Toole JC, Huang N and McCouch SR 1995 Locating genes associated with root morphology and drought avoidance in rice via linkage to molecular markers. Theor ApplGenet. 90 : 969-981.

Cooper M, Rajatasereekul S, Immark S, Fukai S and Basnayake J 1999a Rainfed lowland rice breeding strategies for northeast Thailand 1- Genotypic variation and genotype environment interactions for grain yield. Field Crops Research. 64: 131-152.

Cooper M, Rajatasereekul S, Somrith B, Sriwisut S, Immark S, Boonwite C, Suwanwongse A, Ruangsook S, Hanviriyapant P, Romyen P, Pornuraisanit P, Skulkhu E, Fukai S, Basnayake L and Podlich DW 1999b Rainfed lowland rice breeding strategies for northeast Thailand 2-Comparison of intrastation and interstation selection. Field Crops Research. 64: 153-176.

Ekanayake IJ, O'Toole JC, Garriff DP, Masajo TM, 1985 Root pulling resistance and association with drought tolerance. Euphytica 34:905-913

Gao LZ, Zhang CH, Chang LP, Jia JZ, Qiu ZE, Dong YS 2005 Microsatellite diversity within Oryza sativa with emphasis on indica-japonica divergence. Genet Res. 85(1):1-14.

Hemamalini GS, Sashidhar HE and Hittalmani S 2000 Molecular marker assisted tagging of morphological and physiological traits under two contrasting moisture regimes at peak vegetative stage in rice (Oryza sativa L.). Euphytica. 112: 1 -10 .

Hirayama M, Wada Y and Nemoto H 2006 Estimation of drought tolerance based on leaf temperature in upland rice breeding. Breeding Science. 56: 47-54.

Jearakongman S 2005 Validation and discovery of quantitative trait loci for drought tolerance in backcross introgression lines in Rice (Oryza sativa L.). Cultivar IR64. PhD Thesis. Kasetsart University, p. 95.

Kamoshita A, Wade LJ, Ali, ML, Pathan MS, Zhang J, Sarkarung S, Nguyen HT, 2002a. Mapping QTLs for root morphology of a rice population adapted to rainfed lowland conditions. Theo- retical Applied Genetics 104, 880-893.

Kamoshita A, Zhang J, Siopongco J, Sarkarung S, Nguyen HT, Wade LJ, 2002b. Effects of phenotyping environment on identification of QTL for rice root morphology under anaerobic conditions. Crop Science 42, 255-265.

Kamoshita AM, Babu RC, Boopathi NM and Fukai S 2008 Phenotypic and genotypic analysis of drought-resistance traits for development of rice cultivars adapted to rainfed environments. Field Crops Research. 109:1-23.

Kumar R, Malaiya S and Srivastava MN 2004 Evaluation of morphophysiological traits associated with drought tolerance in rice. Indian Journal of Plant Physiology. 9: 305-307.

Lafitte HR, Vijayakumar CHM, Gao YM, Shi Y, $\mathrm{Xu}$ JL, Fu BY, Yu SB, Ali AJ, Domingo J, Maghirang R, Torres $\mathrm{R}$, Mackill $\mathrm{D}$ and $\mathrm{Li} \mathrm{ZK}$ 2004 Improvement of rice drought tolerance through backcross breeding: evaluation of donors and results from drought nurseries. Field Crop Research. 97: 77-86

Lafitte R and Courtois B 2002. Interpreting cultivar environment interactions for yield in upland rice: assigning value to drought-adaptive traits. Crop Science. 42: 1409-1420.

Lanceras JC, Pantuwan G, Jongdee B and Toojinda T 2004 Quantitative trait loci associated with drought tolerance at reproductive stage in rice. Plant Physiology. 135: 384-399.

Li Z, Mu P, Li C, Zhang H, Li Z, Gao Y and Wang X 2005 QTL mapping of root traits in a double haploid population from a cross between upland and lowland Japonica rice in three environments. Theor. Appl. Genet.110: 1244-1252.

Lilley JM and Fukai S 1994 Effect of timing and severity of water deficit on four diverse rice cultivars I. Rooting pattern and soil water extraction. Field Crops Research. 37:205-213.

Mitchell JH, Siamhan D, Wamala MK, Risimeri JB, Chinyamakobuv E, Henderson SA, Fukai S, 1998 The use of seedling leaf death score for evaluation of drought resistance of rice. Field Crops Research. 55;129-139

O'Toole JC 2004 Rice and water: the final frontier. pp. 12-29. In: Vanavichit A (ed.) Proceedings of the 1st International Conference on Rice for the Future. Kasetsert University, Bangkok. Bangkok, Thailand, 31 August to 2 September: Kasetsart University; National Center for Genetic Engineering and Biotechnology, and Rice Research Institute, Ministry of Agriculture and Cooperatives,

O'Toole JC, Aquino RS and Alluri K 1978 Seedling stage drought response in rice. Agronomy Journal. 70: 1101-1103.

Pandey S, Behura D, Villano R and Naik D 2000 Economic cost of drought and farmers' coping mechanisms: a study of rainfed rice in eastern 
India. IRRI Discussion Paper Series. 39:1-35.

Pantuwan G, Fukai S, Cooper M, Rajatasereekul S, O'Toole JC and Basnayake J 2004 Drought resistance among diverse rainfed lowland rice (Oryza sativa L.) genotypes screened at the vegetative stage in dry season and its association with grain yield obtained under drought conditions in wet season. Field Crops Research. 89: 281-297.

Pinheiro B and Da S 2004 Integrating selection for drought tolerance into a breeding program: the Brazilian experience. pp. 75-83. In: Fischer KS, Lafitte R, Fukai S, Atlin G, Hardy B (eds.) Breeding Rice for Drought-prone Environments. International Rice Research Institute, Los Banos, Philippines.

Pinheiro B, Da S, De Castro E, Da M, Guimaraes CM, 2006 Sustainability and profitability of aerobic rice production in Brazil. Field Crops Research. 97:34-42.

Robin S, Pathan MS, Courtois B, Lafitte R, Carandang S, Lanceras S, Amante M, Nguyeen HT and Li Z 2003 Mapping osmotic adjustment in an advanced back-cross inbred population of rice. Theor Appl Genet.107: 1288-1296.

Samson BK, Hasan M and Wade LJ 2002. Penetration of hardpans by rice lines in the rainfed lowlands. Field Crops Research. 76: 175-188.

Sun Q-S, and Zhang W-X 1995 Inheritance and correlation of root characteristics and leaf water potential in rice (Oryza sativa L.). Sci Agri Sin. 28: 42-48.

Umayal L, Babu RC and Sadasivam S 2001 Water stress induced histological and enzymatic changes in roots of rice cultivars. Plant Archives. 1: 31 34.

Wang XS, Zhu J, Mansueto L and Bruskiewich R 2005 Identification of candidate genes for drought stress tolerance in rice by the integration of a genetic (QTL) map with the rice genome physical map. J. Zhejiang Univ Sci B. 6: 382388.

Yadav R, Courtois B, Huang N and McLaren G 1997 Mapping genes controlling root morphology and root distribution in a doubled-haploid population of rice. Theoretical Applied Genetics. 94: 619-632.

Yang J-C, Wang Z-Q, Zhu Q-S 1995 Relationship between free proline accumulation and the drought tolerance in rice plants under different status of soil moisture. Chinese J Rice Sci. 9: 92-
96.

Yoshida S and Hasegawa S 1982 The rice root system: its development and function. pp. 97-114. In:O'Toole JC (ed.) Drought Resistance in Crops with the Emphasis on Rice. International Rice Research Institute, Los Baños, Philippines.

Yue B, Xue W, Luo L and Xing JY 2008 Identification of quantitative trait loci for four morphologic traits under water stress in rice (Oryza sativa L.). Genet. Genomics. 35:569-575.

Yue, B., Xiong, L., Xue, W., Xing, Y., Luo, L., Xu, C., 2005. Genetic analysis for drought resistance of rice at reproductive stage in field with different types of soil. Theoretical Applied Genetics 111, 1127-1136

Zeigler RS and Puckridge DW 1995 Improving sustainable productivity in rice based rainfed lowland systems of south and southeast Asia. Feeding four billion people. The challenge for rice research in the 21 st century. Geo Journal. 35: 307-324.

Zhang J, Zheng HG, Aarti A, Pantuwan G, Nguyen TT, Tripathy JN, Sarial AK, Robin S, Babu RC, Nguyen BD, Sarkarung S, Blum A and Nguyen HT 2001 Locating genomic regions associated with components of drought resistance in rice: comparative mapping within and across species. Theor. Appl. Genet. 103:19-29.

Zhang J, Zheng HG, Ali ML, Tripathy JN, Aarti A, Pathan MS, Sarial AK, Robin S, Nguyen TT, Babu RC, Nguyen BD, Sarkarung S, Blum A, and Nguyen HT 1999 Progress on the molecular mapping of osmotic adjustment and root traits in rice. In: Ito O, O'Toole JC, and Hardy B (ed) Genetic improvement of rice for water-limited environments: proceedings of the workshop on Genetic Improvement of Rice for Water limited Environments. 1-3 Dec 1998, Los Banos, Philippines. Los Banos, Philippines: International Rice Research Institute. pp. 307-317

Zhou S-H, Tian F, Zhu Z-F, Fu Y-C, and Wang XK 2006 Identification of Quantitative Trait Loci Controlling Drought Tolerance at Seedling Stage in Chinese Dongxiang Common Wild Rice (Oryza rufipogon Griff.). SUN Chuan-Qing Acta Genetica Sinica. 33:551-558.

Zou GH, Mei HW, Liu HY, Liu GL, Hu SP, Yu XQ, Li MS, Wu JH and Luo LJ 2005 Grain yield responses to moisture regimes in a rice population: association among traits and genetic markers. Theoretical Applied Genetics. 112:106-113. 